\title{
Analyzing and evaluation of effective parameters on sound transmission loss of the triple-layered acoustic panels with sound-absorbing middle layer
}

\author{
Nader Mohammadi \\ Department of Mechanical Engineering, Islamic Azad University, Parand Branch, Tehran, Iran \\ E-mail:nmohamady@ut.ac.ir
}

Copyright $\odot 2015$ Nader Mohammadi. This is an open access article distributed under the Creative Commons Attribution License, which permits unrestricted use, distribution, and reproduction in any medium, provided the original work is properly cited.

\begin{abstract}
In this research, a triple-layered acoustic panel with sound-absorbing intermediate layer materials is modeled analytically in order to calculate the sound transmission loss in the normal incidence field. This information provides an appropriate platform for optimum noise control. In this paper, porous material is used as an absorbent layer between two elastic panels. In modeling these triple-layered panels, theory of wave propagation in porous materials is used and bounded boundary condition of the first elastic layer and unbounded boundary condition of the second elastic layer is applied. To validate the model, the results of this model are compared with the results of the Bolton. Comparison of results revealed very good compatibility. Here, the effect of the length of the air gap between the elastic layers, density and the material of the elastic plate, the thickness and vibro-acoustic properties of the intermediate porous material on the values of transmission loss is investigated.

In a wide range of frequencies, increasing air gap, density of elastic panels and porous layer thickness, increase the transmission loss up to $10 \mathrm{~dB}$. At frequencies above $10 \mathrm{kHz}$, a reduction in porosity, static Young's modulus, the loss coefficient, increasing bulk density of the solid phase, the factor of geometrical structure and viscosity of porous material, increase the sound transmission loss up to $15 \mathrm{~dB}$.
\end{abstract}

Keywords: Absorbing Materials; Acoustic Panels; Transmission Loss; Wave Propagation.

\section{Introduction}

Multiple-layered panels in comparison with single-layered panel are used in many engineering applications due to their higher efficiency in acoustic isolation in a wide range of frequencies. Although thin, flat or curved elastic panels with an intermediate layer of porous material, are used in many practical applications, it is very difficult to analyze the sound transmission of these panels. Therefore, the sound transmission of flat or curved panels has been studied by many researchers in the past and it is still considered in the current investigations.

Biot [1] presented a theory of wave propagation in a porous elastic solid containing a compressible viscous fluid, in two parts. The emphasis of the research was on the materials that have both fluid and solid phases. The first part of his study is limited to low frequencies, where the assumption Poiseuille flow is valid. In this study, porous material is demonstrated by four dimensionless parameters and a specific frequency. The physical interpretations of the results are described, where the fluid is assumed to be frictionless. Propagation curves of velocity phases and damping coefficients for three types of waves are plotted as a function of frequency, for different combinations of certain parameters. In the second part of his study [2], the theory of wave propagation in a porous elastic solid is presented for high frequencies. Just like the first part, the focus is on materials that are contains the fluid and solid phases. Here again, propagation curves of velocity phases and damping coefficients for three types of waves are plotted as a function of frequency, for six different combinations of certain parameters. In this study, the behavior of the flanking paths at higher frequencies is discussed. 
Bolton and Green [3] investigated the sound transmission of triple-layered panel with porous (polyurethane foam) intermediate layer materials. Here, a theory for one-dimensional wave propagation in porous media that allows the two types of longitudinal waves (air-borne sound wave and structure-borne sound wave) pass continually is used. Also, the effect of boundary conditions and connecting foam on the values of transmission sound is discussed. In this research, the effective parameters such as bulk modulus, loss coefficient, fluid resistance and structure factor are investigated. Measurements related to the response of the shock wave, clearly indicates the presence of both air-borne sound wave and structure-borne sound wave. The theoretical values of the transmission loss are also provided. The most important result of the transmission loss values is that the boundary condition between the foam and elastic layers has a significant effect on the performance of acoustic panel. Also, in this study it is declared that unbounded boundary condition of the foam and elastic plate (by an air gap) represents an optimal acoustic performance of the panels. These types of connection minimize the mass-air-mass resonance which is usually weakened the sound transmission loss at low frequencies and provides good performance at higher frequencies.

Panneton et al. [4] computed the values of sound transmission loss in multi-layered acoustic panels with the middle layer of porous isotropic layers in the normal incidence field. In this study, in order to optimize the sound transmission loss, a three-dimensional finite element model with the ability of modeling the boundary conditions (high precision) is used. Here, the Biot theory of wave propagation in porous material is applied.

Bolton et al. [5] measured the values of sound transmission loss in triple-layered acoustic panels with the middle layer of porous isotropic layers in the random incidence field. In this study, the values of the transmission loss are also calculated theoretically. Here, the theory of wave propagation in porous materials provided by Biot had been used. In this study, the governing equations of wave propagation in a porous material are presented and the relationship between stress and displacement in porous material has been obtained. Also, the boundary conditions needed for modeling the problem has been presented and discussed. The results show that the boundary conditions of connecting the porous material have a significant effect on the values of transmission loss. In the case that the elastic plate is attached to the porous material indirectly, in comparison with the case that is directly in contact panel, triple-layered panels represent better acoustic performance.

Tang et al. [6] studied the airborne sound transmission through an infinite cylindrical sandwich panel. In this study, cylindrical shell immersed in a fluid environment and a plane sound wave in a random field encounters. Inner and outer fluids of the shell are different and uniform air flow is passing through the outer environment of the fluid. They offered a direct relationship to the values of transmission loss in terms of fluid and cylindrical shell impedance. Also, the effect of the incidence angles of the plane wave, the ratio of core to the whole shell thickness and loss coefficient on the sound transmission loss has been investigated.

Atalla et al. [7] calculated sound transmission loss values of the acoustic multi-layered panels with the middle layer of porous material. In this paper, multilayer panels are modeled using finite element and boundary element methods. Also, the effect of parameters such as the arrangement of the layers, the material of the porous layer and conditions of the arrangement on the values of transmission loss is investigated.

Lee and Kim [8] proposed a simple analytical method for the calculation of sound transmission loss values of the acoustic multilayer panels with a middle layer of porous material. In the modeling of porous materials, only the largest component of the wave is considered.

Mohammadi et al. [9-12] obtained sound transmission loss values of the triple-layered acoustic panels with the middle layer of a smart fluid analytically and empirically. The intelligent fluid is assumed to be a Newtonian fluid. In order to model the panel with the middle layer of a Newtonian fluid, the Impedance Progressive Model (IPM) and the Progressive Wave Model (PWM) were used. Then the smart MR fluid elastic model has been modeled using a complex modulus model. Also, the sound transmission loss values of the triple-layered acoustic panels with smart fluid MR intermediate layer are determined under external magnetic field both analytically and empirically. The results represent an increase in sound transmission loss by increasing the magnetic field.

Daneshju et al. [13] modeled the wave propagation in a double layer cylindrical sandwich composite shell with middle layer of porous materials. The porous layer is modeled as a fluid with equivalent properties. Also the sound transmission loss values are evaluated in a specified frequency range.

Shojaeifard et al. [14] calculated the wave propagation in a double layer cylindrical sandwich composite shell with middle layer of porous materials. The results showed that by increasing the thickness of the porous material, the values of sound transmission loss increased significantly. Additionally, at the lower frequencies the values of transmission loss increases with increasing axial modulus of thin films.

The purpose of this study is the analytical modeling of a triple-layered acoustic panel with sound-absorbing intermediate layer materials in the normal incidence field. The effect of the length of the air gap between the elastic layers, density and the material of the elastic plate, the thickness of the intermediate porous material and vibro-acoustic properties of porous material, on the values of transmission loss is investigated. 


\section{The modeling of wave propagation in porous materials}

In this section, the used theory for describing wave propagation in porous materials is presented. The proposed theory [3-15] is almost on the basis of Biot theory [1,2] and in many respects is similar to Allard's theory [15, 16].

\subsection{Stress-strain relations}

According to Biot $[1,2]$, the relationship between strains of solid and liquid phases and the force per unit area of the solid phase (in x direction), $\sigma_{x}$, is expressed as follows:

$\sigma_{x}=2 N e_{x}+A e_{S}+Q \varepsilon$

In Eq. (1), $e_{s}=\nabla \cdot \bar{u}$ is the volumetric strain of solid phase in which, $\bar{u}$ is the displacement field vector of solid phase. Also, $e_{x}=\partial u_{x} / \partial x$, where $u_{x}$ is the x component of displacement vector. $\varepsilon=\nabla \cdot \bar{U}$ is the volumetric strain, where $\bar{U}$ is the displacement field vector of fluid. $\mathrm{N}$ is the shear modulus, which is equal to $E_{1} / 2(1+v)$, where $E_{1}$ is the Young's modulus in solid phase and $v$ is the Poisson's ratio. $A$ is the first Lamé constant, equal to $v E_{1} /[(1+v)(1-2 v)] . Q$ is a positive number and represent a coupling between volumetric conversion from solid phase to fluid phase [1, 2]. Comparing of the Eq. (1) and the available theories of wave propagation in one-dimensional porous material, $Q$ is equal to $(1-h) E_{2}$, in which, $h$ is the porosity and $E_{2}$ is the fluid phase modulus of elasticity in pores. Parameter $h$ generally depends on frequency and represents the part of the stiffness of the fluid phase within the pores of the material, allowing the energy dissipation due to the heat exchange with the walls of the pores. Similar relations for the forces acting on the surface of the solid phase, in the directions $y$ and $\mathrm{z}$, are as follows:

$\sigma_{y}=2 N e_{y}+A e_{s}+Q \varepsilon$

And

$\sigma_{z}=2 N e_{z}+A e_{s}+Q \varepsilon$

Where, $e_{y}=\partial u_{y} / \partial y \quad\left(u_{y}\right.$ is the y component of displacement vector) and $e_{z}=\partial u_{z} / \partial z \quad\left(u_{z}\right.$ is the z component of displacement vector).

Force per unit area of porous material in the liquid phase explained as follows:

$s=R \varepsilon+Q e_{s}$

In the Eq. (4), $\mathrm{S}$ in a tensile mode is intended with a negative sign. Also, R constant is the relationship between stress and strain in the liquid phase and equal to $h E_{2}$ [1], [2] and [15]. Constant values of the parameters $\mathrm{Q}$ and $\mathrm{R}$ can be obtained experimentally [17].

Shear forces exerted on the solid phase, on x-y plane, expressed as follows:

$\tau_{x y}=\tau_{y x}=N \gamma_{x y}$

In the above equation, the shear strain $\gamma_{x y}$ is equal to $\partial u_{x} / \partial y+\partial u_{y} / \partial x$. Similarly, the shear forces acting on planes $\mathrm{X}-\mathrm{z}$ and $\mathrm{y}-\mathrm{z}$ are as follows, respectively:

$\tau_{x z}=\tau_{z x}=N \gamma_{x z}$

And

$\tau_{y z}=\tau_{z y}=N \gamma_{y z}$

\subsection{Motion equation}

For solid phase, motion equation in $\mathrm{x}$ direction can be expressed as below: 
$\frac{\partial \sigma_{x}}{\partial x}+\frac{\tau_{y x}}{\partial y}+\frac{\partial \tau_{z x}}{\partial z}=\rho_{1} \frac{\partial^{2} u_{x}}{\partial t^{2}}+\rho_{a} \frac{\partial^{2}}{\partial t^{2}}\left(u_{x}-U_{x}\right)+b \frac{\partial}{\partial t}\left(u_{x}-U_{x}\right)$

Where, $\rho_{1}$ is the bulk density of solid phase $\rho_{a}$ is the coupling parameter and $\mathrm{b}$ is the viscous coupling coefficient that can be a function of flow resistance of macroscopic porous material. Equations of motion in $\mathrm{z}$ and $\mathrm{y}$ direction can be expressed as below, respectively:

$$
\frac{\partial \sigma_{y}}{\partial y}+\frac{\tau_{x y}}{\partial x}+\frac{\partial \tau_{z y}}{\partial z}=\rho_{1} \frac{\partial^{2} u_{y}}{\partial t^{2}}+\rho_{a} \frac{\partial^{2}}{\partial t^{2}}\left(u_{y}-U_{y}\right)+b \frac{\partial}{\partial t}\left(u_{y}-U_{y}\right)
$$

And

$\frac{\partial \sigma_{z}}{\partial z}+\frac{\tau_{x z}}{\partial x}+\frac{\partial \tau_{y z}}{\partial z}=\rho_{1} \frac{\partial^{2} u_{z}}{\partial t^{2}}+\rho_{a} \frac{\partial^{2}}{\partial t^{2}}\left(u_{z}-U_{z}\right)+b \frac{\partial}{\partial t}\left(u_{z}-U_{z}\right)$

For fluid phase, motion equations in $\mathrm{x}, \mathrm{y}$ and $\mathrm{z}$ directions can be expressed as below:

$\frac{\partial s}{\partial x}=\rho_{2} \frac{\partial^{2} U_{x}}{\partial t^{2}}+\rho_{a} \frac{\partial^{2}}{\partial t^{2}}\left(U_{x}-u_{x}\right)+b \frac{\partial}{\partial t}\left(U_{x}-u_{x}\right)$

And

$\frac{\partial s}{\partial y}=\rho_{2} \frac{\partial^{2} U_{y}}{\partial t^{2}}+\rho_{a} \frac{\partial^{2}}{\partial t^{2}}\left(U_{y}-u_{y}\right)+b \frac{\partial}{\partial t}\left(U_{y}-u_{y}\right)$

Also,

$\frac{\partial s}{\partial z}=\rho_{2} \frac{\partial^{2} U_{z}}{\partial t^{2}}+\rho_{a} \frac{\partial^{2}}{\partial t^{2}}\left(U_{z}-u_{z}\right)+b \frac{\partial}{\partial t}\left(U_{z}-u_{z}\right)$

Where, $\rho_{2}$ is the bulk density of fluid phase and it is equal to $\rho_{0} h$ and $\rho_{0}$ is the mean density of fluid.

\subsection{Wave equation}

Replacing the Eqs. (1) to (7) in motion equations of (8) to (13), gives the relation between displacements and strains.

$N \nabla^{2} \bar{u}+\nabla\left[(A+N) e_{s}+Q \varepsilon\right]=-\omega^{2}\left(\rho_{11}^{*} \bar{u}+\rho_{12}^{*} \bar{U}\right)$

And

$\nabla\left(Q e_{s}+R \varepsilon\right)=-\omega^{2}\left(\rho_{12}^{*} \bar{u}+\rho_{22}^{*} \bar{U}\right)$

Where, $\rho_{11}^{*}=\rho_{11}+b / \mathrm{j} \omega, \rho_{11}=\rho_{1}+\rho_{a}, \rho_{12}^{*}=\rho_{12}-b / \mathrm{j} \omega, \rho_{12}=-\rho_{a}, \rho_{22}^{*}=\rho_{22}+b / \mathrm{j} \omega$ and $\rho_{22}=\rho_{2}+\rho_{a} \cdot \rho_{11}, \rho_{12}$ and $\rho_{22}$ parameters are the calculated mass coefficient for nonunimform fluid flow effects in pores. $\rho_{11}^{*}, \rho_{12}^{*}$ and $\rho_{22}^{*}$ are the respective parameters of $\rho_{11}, \rho_{12}$ and $\rho_{22}$ in which, viscous energy dissipation due to the relative motion between solid and fluid phase of porous is considered. Eqs. (14) And (15) can be written as follows:

$\nabla^{2}\left(P e_{s}+Q \varepsilon\right)=-\omega^{2}\left(\rho_{11}^{*} e_{s}+\rho_{12}^{*} \varepsilon\right)$

And

$\nabla^{2}\left(Q e_{s}+R \varepsilon\right)=-\omega^{2}\left(\rho_{12}^{*} e_{s}+\rho_{22}^{*} \varepsilon\right)$

Where, $P=A+2 N$. When the porous material is isotropic, the Eqs. (16) And (17) may be expressed as follows:

$Q \nabla^{2} \varepsilon+\omega^{2} \rho_{12}^{*} \varepsilon=-P \nabla^{2} e_{s}-\omega^{2} \rho_{11}^{*} e_{s}$ 
And

$R \nabla^{2} \varepsilon+\omega^{2} \rho_{22}^{*} \varepsilon=-Q \nabla^{2} e_{S}-\omega^{2} \rho_{12}^{*} e_{s}$

Solving the above equation results:

$\nabla^{2} \varepsilon=\frac{\left(\rho_{12}^{*} Q-\rho_{22}^{*} P\right) \nabla^{2} e_{s}+\omega^{2}\left[\left(\rho_{12}^{*}\right)^{2}-\rho_{11}^{*} \rho_{22}^{*}\right] e_{s}}{\rho_{22}^{*} Q-\rho_{12}^{*} R}$

And

$\varepsilon=\frac{\left(P R-Q^{2}\right) \nabla^{2} e_{s}+\omega^{2}\left(\rho_{11}^{*} R-\rho_{12}^{*} Q\right) e_{s}}{\omega^{2}\left(\rho_{22}^{*} Q-\rho_{12}^{*} R\right)}$

From Eqs. (20) And (21), we can obtain:

$\nabla^{4} e_{s}+A_{1} \nabla^{2} e_{s}+A_{2} e_{s}=0$

Where, the $A_{1}$ and $A_{2}$ coefficients can be expressed as follows:

$A_{1}=\frac{\omega^{2}\left(\rho_{11}^{*} R-2 \rho_{12}^{*} Q+\rho_{22}^{*} P\right)}{P R-Q^{2}}$

And

$A_{2}=\frac{\omega^{4}\left[\rho_{11}^{*} \rho_{22}^{*}-\left(\rho_{12}^{*}\right)^{2}\right]}{P R-Q^{2}}$

The Eq. (22) represents the longitudinal wave propagation in solid phase. When a harmonic solution in the form of $\mathrm{e}^{\mathrm{j}(\omega t-\bar{k} \bar{r})}$ is expected ( $\bar{k}$ is the wave vector and $\bar{r}$ is the position vector), we can obtain two solutions by replacing the solution in Eq. (22), where the wave numbers can be expressed as follow:

$k_{1,2}^{2}=\left(A_{1} \pm \sqrt{A_{1}^{2}-4 A_{2}}\right) / 2$

Thus, two longitudinal waves are propagated in a porous material with different wave numbers. One of these waves has been known as structure-borne sound wave and the other as air-borne sound wave. Parameters of structure-borne sound wave were calculated by the bulk elastic properties of material and parameters of air-borne sound wave by the acoustic properties of the fluid phase of the wave propagation such as porosity, flow resistance, etc. [18]. As shown in the next solutions, both structure-borne sound wave and air-borne sound wave has been observed in both phases of porous material observed.

From Eqs. (14) and (15) we have:

$-\omega^{2}\left(\rho_{11}^{*} \bar{\omega}+\rho_{12}^{*} \bar{\Omega}\right)=N \nabla^{2} \bar{\omega}$

And

$-\omega^{2}\left(\rho_{12}^{*} \bar{\omega}+\rho_{22}^{*} \bar{\Omega}\right)=0$

From Eqs. (26) And (27), the wave equation of rotational wave propagation in solid phase can be written as below:

$\nabla^{2} \bar{\omega}+k_{t}^{2} \bar{\omega}=0$

Where

$k_{t}^{2}=\frac{\omega^{2}}{N}\left[\frac{\rho_{11}^{*}-\left(\rho_{12}^{*}\right)^{2}}{\rho_{22}^{*}}\right]$ 


\subsection{The solution in terms of the field variables}

As shown in Fig. 1, a vertical plane wave encounters a layer of porous material. The direction of wave propagation is parallel to the $\mathrm{x}-\mathrm{y}$ plane.

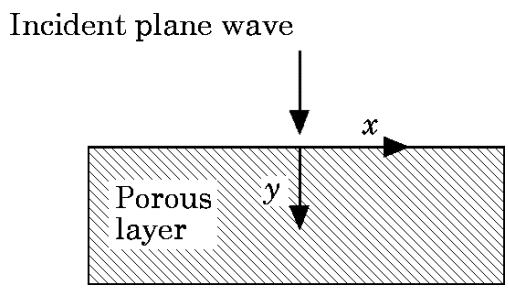

Fig. 1: The Vertical Plane Wave Encounters a Layer of Porous Material

A two-dimensional solution of the Eq. (22) for solid strain values, in x-y plane, is as follows:

$e_{s}=\mathrm{e}^{-\mathrm{j} k_{x} x}\left(C_{1} \mathrm{e}^{-\mathrm{j} k_{1 y} y}+C_{2} \mathrm{e}^{\mathrm{j} k_{1 y} y}+C_{3} \mathrm{e}^{-\mathrm{j} k_{2 y} y}+C_{4} \mathrm{e}^{\mathrm{j} k_{2 y} y}\right)$

From Eq. (21), we can directly calculate the fluid strain:

$\varepsilon=\mathrm{e}^{-\mathrm{j} k_{x} x}\left(b_{1} C_{1} \mathrm{e}^{-\mathrm{j} k_{1 y} y}+b_{1} C_{2} \mathrm{e}^{\mathrm{j} k_{1 y} y}+b_{2} C_{3} \mathrm{e}^{-\mathrm{j} k_{2 y} y}+b_{2} C_{4} \mathrm{e}^{\mathrm{j} k_{2 y} y}\right)$

In Eqs. (30) And (31), $k_{1,2 y}^{2}=k_{1,2}^{2}-k_{x}^{2}, a_{1}=\frac{\rho_{11}^{*} R-\rho_{12}^{*} Q}{\rho_{22}^{*} Q-\rho_{12}^{*} R}, b_{1}=a_{1}-a_{2} k_{1}^{2}, a_{2}=\frac{P R-Q^{2}}{\omega^{2}\left(\rho_{22}^{*} Q-\rho_{12}^{*} R\right)}$ and $b_{2}=a_{1}-a_{2} k_{2}^{2}$.

Similiarly, one solution of Eq. (28) for rotational strain in solid phase can be expressed as follows:

$\omega_{z}=\mathrm{e}^{-\mathrm{j} k_{x} x}\left(C_{5} \mathrm{e}^{-\mathrm{j} k_{t y} y}+C_{6} \mathrm{e}^{\mathrm{j} k_{t y} y}\right)$

Where, $k_{t y}^{2}=k_{t}^{2}-k_{x}^{2}$. By replacing Eq. (32) to (27), rotational strain of fluid can be written as below:

$\Omega_{z}=g \mathrm{e}^{-\mathrm{j} k_{x} x}\left(C_{5} \mathrm{e}^{-\mathrm{j} k_{t y} y}+C_{6} \mathrm{e}^{\mathrm{j} k_{t y} y}\right)$

Where, $g=-\rho_{12}^{*} / \rho_{22}^{*}$. In Eqs. (30) to (33), $C_{1}$ to $C_{6}$ be the constant parameters obtained from boundary conditions.

Volumetric strain of the solid and fluid phases is dependent on two wavelengths, whereas the rotational strains are associated with a transverse wave. All variables of the displacement field should include combinations of each six components of the wave (positive and negative directions of two longitudinal waves and a transverse wave). Thus, the solid phase displacement components in the $\mathrm{x}$ and $\mathrm{y}$ directions are expressed as follows:

$u_{x}=u_{1 x}+u_{t x}=\mathrm{e}^{-\mathrm{j} k_{x} x}\left(D_{1} \mathrm{e}^{-\mathrm{j} k_{1 y} y}+D_{2} \mathrm{e}^{\mathrm{j} k_{1 y} y}+D_{3} \mathrm{e}^{-\mathrm{j} k_{2 y} y}+D_{4} \mathrm{e}^{\mathrm{j} k_{2 y} y}+D_{5} \mathrm{e}^{-\mathrm{j} k_{t y} y}+D_{6} \mathrm{e}^{\mathrm{j} k_{t y} y}\right)$

And

$u_{y}=u_{1 y}+u_{t y}=\mathrm{e}^{-\mathrm{j} k_{x} x}\left(D_{7} \mathrm{e}^{-\mathrm{j} k_{1 y} y}+D_{8} \mathrm{e}^{\mathrm{j} k_{1 y} y}+D_{9} \mathrm{e}^{-\mathrm{j} k_{2 y} y}+D_{10} \mathrm{e}^{\mathrm{j} k_{2 y} y}+D_{11} \mathrm{e}^{-\mathrm{j} k_{t y} y}+D_{12} \mathrm{e}^{\mathrm{j} k_{t y} y}\right)$

Where, $D_{1}$ to $D_{12}$ are the coefficients of complex values. Also, $u_{1 x}$ and $u_{1 y}$ are the longitudinal waves and $u_{t x}$ and $u_{t y}$ are the transverse waves. The solid phase displacement vector can be expressed as follows:

$\bar{u}=\bar{i} u_{x}+\bar{j} u_{y}=\bar{i}\left(u_{1 x}+u_{t x}\right)+\bar{j}\left(u_{1 y}+u_{t y}\right)=\bar{i}_{1 x}+\bar{j} u_{1 y}+\bar{i}_{t x}+\bar{j} u_{t y}=\bar{u}_{1}+\bar{u}_{t}$

Where, the $\bar{i}$ and $\bar{j}$ are the unit vectors in $\mathrm{x}$ and $\mathrm{y}$ directions. Displacement component in $\mathrm{x}$ and $\mathrm{y}$ directions for solid and fluid phases can be written as follows: 


$$
\begin{aligned}
u_{x}= & \mathrm{j} k_{x} \mathrm{e}^{-\mathrm{j} k_{x} x}\left(\frac{C_{1}}{k_{1}^{2}} \mathrm{e}^{-\mathrm{j} k_{1 y} y}+\frac{C_{2}}{k_{1}^{2}} \mathrm{e}^{\mathrm{j} k_{1 y} y}+\frac{C_{3}}{k_{2}^{2}} \mathrm{e}^{-\mathrm{j} k_{2 y} y}+\frac{C_{4}}{k_{2}^{2}} \mathrm{e}^{\mathrm{j} k_{2 y} y}\right) \\
& -\mathrm{j} \frac{k_{t y}}{k_{t}^{2}} \mathrm{e}^{-\mathrm{j} k_{x} x}\left(C_{5} \mathrm{e}^{-\mathrm{j} k_{t y} y}-C_{6} \mathrm{e}^{\mathrm{j} k_{t y} y}\right)
\end{aligned}
$$

And

$$
\begin{aligned}
u_{y}= & \mathrm{j} \mathrm{e}^{-\mathrm{j} k_{x} x}\left(\frac{k_{1 y}}{k_{1}^{2}} C_{1} \mathrm{e}^{-\mathrm{j} k_{1 y} y}-\frac{k_{1 y}}{k_{1}^{2}} C_{2} \mathrm{e}^{\mathrm{j} k_{1 y} y}+\frac{k_{2 y}}{k_{2}^{2}} C_{3} \mathrm{e}^{-\mathrm{j} k_{2 y} y}-\frac{k_{2 y}}{k_{2}^{2}} C_{4} \mathrm{e}^{\mathrm{j} k_{2 y} y}\right) \\
& +\mathrm{j} \frac{k_{x}}{k_{t}^{2}} \mathrm{e}^{-\mathrm{j} k_{x} x}\left(C_{5} \mathrm{e}^{-\mathrm{j} k_{t y} y}+C_{6} \mathrm{e}^{\mathrm{j} k_{t y} y}\right)
\end{aligned}
$$

Also,

$$
\begin{aligned}
U_{x}= & \mathrm{j} k_{x} \mathrm{e}^{-\mathrm{j} k_{x} x}\left(b_{1} \frac{C_{1}}{k_{1}^{2}} \mathrm{e}^{-\mathrm{j} k_{1 y} y}+b_{1} \frac{C_{2}}{k_{1}^{2}} \mathrm{e}^{\mathrm{j} k_{1 y} y}+b_{2} \frac{C_{3}}{k_{2}^{2}} \mathrm{e}^{-\mathrm{j} k_{2 y} y}+b_{2} \frac{C_{4}}{k_{2}^{2}} \mathrm{e}^{\mathrm{j} k_{2 y} y}\right) \\
& -\mathrm{j} g \frac{k_{t y}}{k_{t}^{2}} \mathrm{e}^{-\mathrm{j} k_{x} x}\left(C_{5} \mathrm{e}^{-\mathrm{j} k_{t} y}-C_{6} \mathrm{e}^{\mathrm{j} k_{t y} y}\right)
\end{aligned}
$$

And

$$
\begin{aligned}
U_{y}= & \mathrm{j} \mathrm{e}^{-\mathrm{j} k_{x} x}\left(b_{1} \frac{k_{1 y}}{k_{1}^{2}} C_{1} \mathrm{e}^{-\mathrm{j} k_{1 y} y}-b_{1} \frac{k_{1 y}}{k_{1}^{2}} C_{2} \mathrm{e}^{\mathrm{j} k_{1 y} y}+b_{2} \frac{k_{2 y}}{k_{2}^{2}} C_{3} \mathrm{e}^{-\mathrm{j} k_{2 y} y}-b_{2} \frac{k_{2 y}}{k_{2}^{2}} C_{4} \mathrm{e}^{\mathrm{j} k_{2 y} y}\right) \\
& +\mathrm{j} g \frac{k_{x}}{k_{t}^{2}} \mathrm{e}^{-\mathrm{j} k_{x} x}\left(C_{5} \mathrm{e}^{-\mathrm{j} k_{t y} y}+C_{6} \mathrm{e}^{\mathrm{j} k_{t} y}\right)
\end{aligned}
$$

By replacing the Eqs. (30), (31) and (37) to (40) in Eqs. of (2), (4) and (5), gives the explicit equation for $\sigma_{y}, s$ and $\tau_{x y}$ as follows:

$$
\sigma_{y}=\mathrm{e}^{-\mathrm{j} k_{x} x}\left[\begin{array}{l}
\left(2 N \frac{k_{1 y}^{2}}{k_{1}^{2}}+A+b_{1} Q\right) C_{1} \mathrm{e}^{-\mathrm{j} k_{1 y} y}+\left(2 N \frac{k_{1 y}^{2}}{k_{1}^{2}}+A+b_{1} Q\right) C_{2} \mathrm{e}^{\mathrm{j} k_{1 y} y} \\
+\left(2 N \frac{k_{2 y}^{2}}{k_{2}^{2}}+A+b_{2} Q\right) C_{3} \mathrm{e}^{-\mathrm{j} k_{2 y} y}+\left(2 N \frac{k_{2 y}^{2}}{k_{2}^{2}}+A+b_{2} Q\right) C_{4} \mathrm{e}^{\mathrm{j} k_{2 y} y} \\
+2 N \frac{k_{x} k_{t y}}{k_{t}^{2}}\left(C_{5} \mathrm{e}^{-\mathrm{j} k_{t y} y}-C_{6} \mathrm{e}^{\mathrm{j} k_{t y} y}\right)
\end{array}\right]
$$

And

$s=\mathrm{e}^{-\mathrm{j} k_{x} x}\left[\left(Q+b_{1} R\right) C_{1} \mathrm{e}^{-\mathrm{j} k_{1 y} y}+\left(Q+b_{1} R\right) C_{2} \mathrm{e}^{\mathrm{j} k_{1 y} y}+\left(Q+b_{2} R\right) C_{3} \mathrm{e}^{-\mathrm{j} k_{2 y} y}+\left(Q+b_{2} R\right) C_{4} \mathrm{e}^{\mathrm{j} k_{2 y} y}\right]$

Also,

$\tau_{x y}=\mathrm{e}^{-\mathrm{j} k_{x} x} N\left[\begin{array}{l}\frac{2 k_{x} k_{1 y}}{k_{1}^{2}}\left(C_{1} \mathrm{e}^{-\mathrm{j} k_{1 y} y}-C_{2} \mathrm{e}^{\mathrm{j} k_{1 y} y}\right)+\frac{2 k_{x} k_{2 y}}{k_{2}^{2}}\left(C_{3} \mathrm{e}^{-\mathrm{j} k_{2 y} y}-C_{4} \mathrm{e}^{\mathrm{j} k_{2 y} y}\right) \\ +\frac{k_{x}^{2}-k_{t y}^{2}}{k_{t}^{2}}\left(C_{5} \mathrm{e}^{-\mathrm{j} k_{t y} y}+C_{6} \mathrm{e}^{\mathrm{j} k_{t y} y}\right)\end{array}\right]$

\subsection{Boundary condition}

In Eqs. (37) to (43), the constants $C_{1}$ to $C_{6}$ can be attained from the boundary conditions of connection between the porous layer and elastic layers. In bounded boundary condition, the middle absorbing layer is connected to both elastic layers directly, without an air gap. In The bounded boundary condition of the first layer and unbounded boundary condition the second layer, absorbent middle layer is attached from one side directly and from the other side by the air 
gap to elastic plates. In unbounded boundary condition of three layers, both elastic plates placed by distance from the middle layer. These three types of boundary condition are shown schematically in Fig. 2.

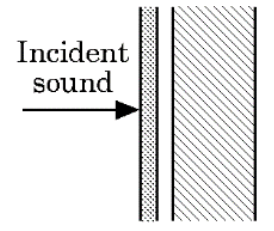

Unbonded (U)

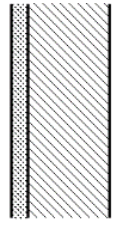

Bonded (B)

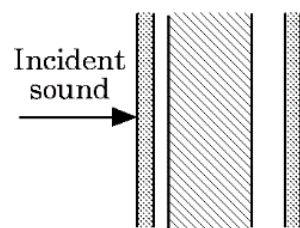

UnbondedUnbonded (UU)

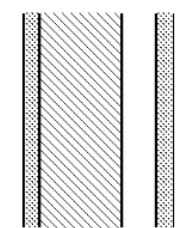

Bonded-

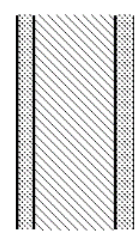

Bonded-

Unbonded (BU) Bonded (BB)

Fig. 2: The Boundary Conditions of Connection of Porous Layer to Elastic Layers

For unbounded boundary condition of porous layer which is shown in Fig. 3, four boundary conditions are established: Two conditions for the normal stress, a condition for the vertical velocity components and a condition for shear stress. These conditions are as follows:

$-h P=s$

And

$-(1-h) P=\sigma_{y}$

Also,

$v_{y}=\mathrm{j} \omega(1-h) u_{y}+\mathrm{j} \omega h U_{y}$

And

$\tau_{x y}=0$

In the above equations, $P$ is the pressure in the air gap and $v_{y}$ is the acoustic elements vertical component of velocity in the air gap.

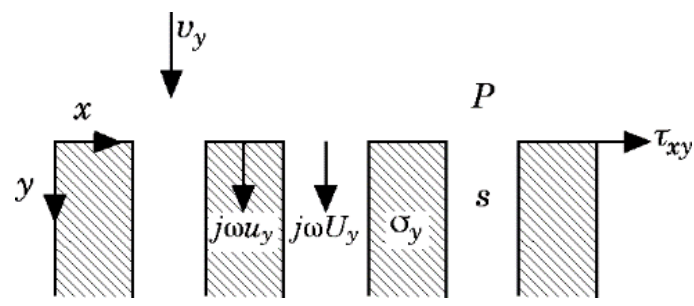

Fig. 3: The Vertical Plane Wave Encounters to the Surface of the Porous Layer

When the porous layer, as shown in Fig. 4, connected to the elastic plate directly, there exist six boundary condition, a condition for vertical speed, two for vertical displacement, one for the tangential displacement, one for the acceleration of the middle layer and a condition for force (motion equation of triple-layer panel). 


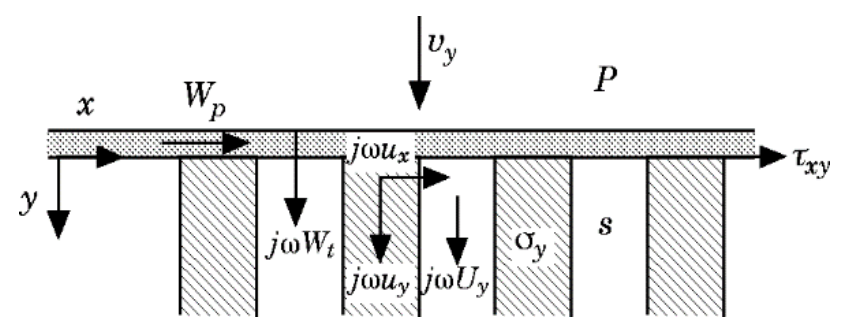

Fig. 4: The Vertical Plane Wave Encounters to the Elastic Plane Attached to the Porous Layer

Assuming that the transverse displacement of the elastic plate is equal to $w_{t}(x, t)=W_{t}(x) \mathrm{e}^{\mathrm{j} \omega t}$ and displacement of the middle layer is $w_{p}(x, t)=W_{p}(x) \mathrm{e}^{\mathrm{j} \omega t}$, the boundary conditions are as follows:

$v_{y}=\mathrm{j} \omega W_{t}$

And

$u_{y}=W_{t}$

Also,

$U_{y}=W_{t}$

And

$u_{x}=W_{p}(-/+) \frac{h_{p}}{2} \frac{\mathrm{d} W_{t}}{\mathrm{~d} x}$

Also,

$(+/-) \tau_{y x}=\left(D_{p} k_{x}^{2}-\omega^{2} m_{s}\right) W_{p}$

And

$(+/-) P(-/+) q_{p}-\mathrm{j} k_{x} \frac{h_{p}}{2} \tau_{x y}=\left(D k_{x}^{4}-\omega^{2} m_{s}\right) W_{t}$

In the above equations, $h_{p}$ is the elastic layer thickness, $\mathrm{D}$ is the flexural stiffness of the unit width of the elastic layer, $D_{p}$ is the longitudinal stiffness of the unit width of the elastic layer, $m_{s}$ is the mass per unit area of the elastic layer and $q_{p}$ is the vertical force by the porous material on the unit surface of elastic layer $\left(q_{p}=-\sigma_{y}-s\right)$. In Eqs. (51) to (53), the first signs, show the case in which the porous material is attached to the elastic layer from the positive direction. If the porous material is attached to a flexible shell, longitudinal flexural stiffness and rigidity of the elastic layer is zero.

For the case in which the porous material is in indirect connection with both elastic layers, the following conditions hold:

$v_{1 y}=\mathrm{j} \omega W_{t}$

And

$v_{2 y}=\mathrm{j} \omega W_{t}$

Also,

$P_{1}-P_{2}=\left(D k_{x}^{4}-\omega^{2} m_{s}\right) W_{t}$ 
Where, $P_{1}$ and $P_{2}$ are the acoustic pressure of air gap between the two sides of the porous material and $v_{1 y}$ and $v_{2 y}$ are the normal acoustic velocities of elements in the air gap.

Here, for modeling the problem, the bounded boundary condition of the first elastic layer along with the unbounded boundary condition to second elastic layer has been considered.

\section{Results}

Bolton has considered three types of connecting absorbing material to elastic layers and showed that the bounded connection of first elastic layer along with unbounded connection of second elastic layer, (B-U construction), is superior to the other two structures. The existing waves in the system and the number of boundary conditions at each boundary of the structure are shown in Fig. 5.

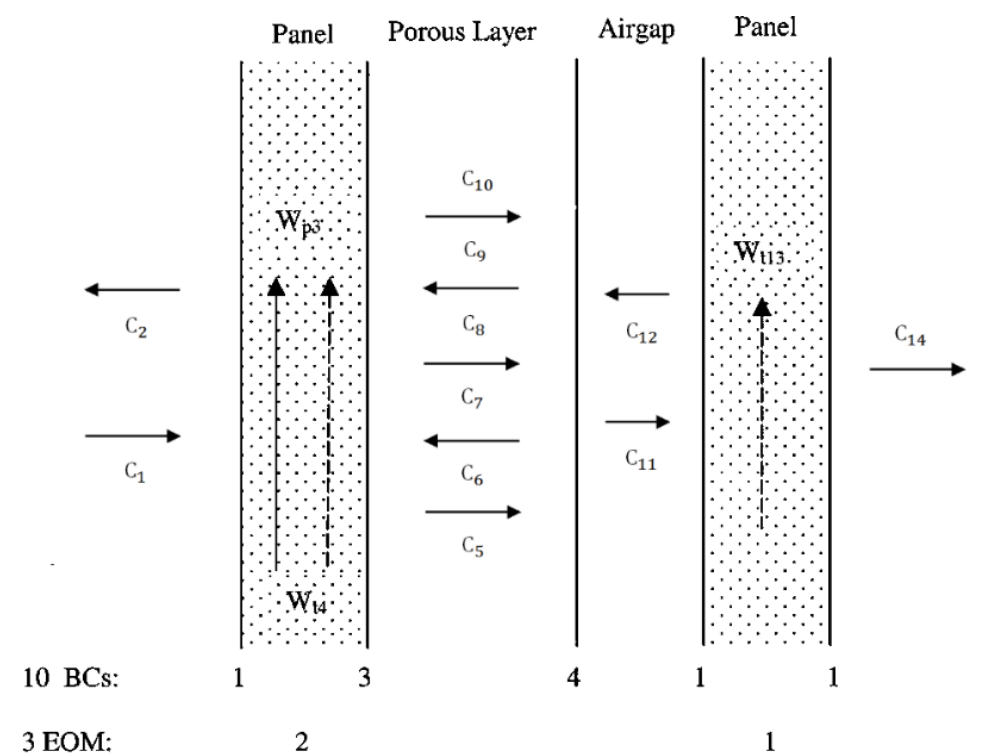

Fig. 5: Existing Waves in the System and the Number of Boundary Conditions at Each Boundary

Thus, a total of 14 waves with 13 boundary conditions exist in the structure, based on which, the sound transmission coefficient can be calculated. Sound transmission coefficient, is the ratio of the amplitude of the incident wave to the amplitude of final transmission sound, which is equal to $\tau=C_{14} / C_{1}$ and is a function of angular frequency. Finally, the transmission loss values are calculated by the following equation:

$$
\mathrm{TL}=10 \log \left(\frac{1}{\tau}\right)
$$

Validate the model, the obtained results from this research have been compared with the Bolton results and shown in Fig. 6. The results show a good agreement with Bolton result.

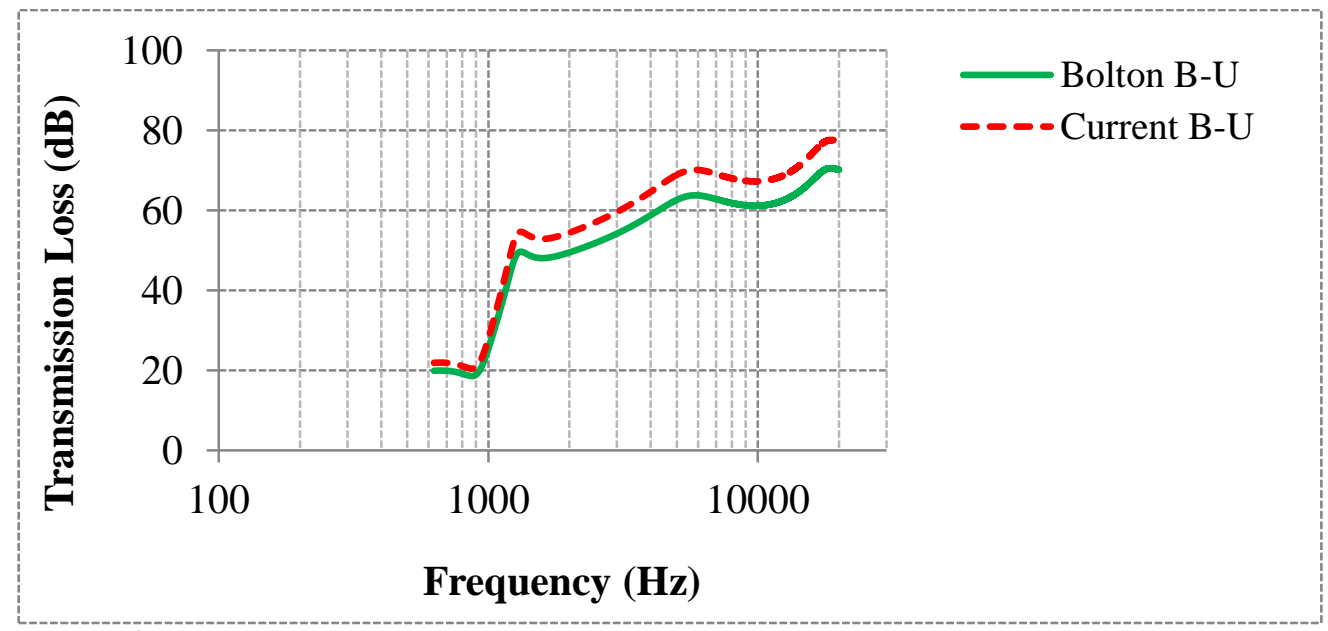

Fig. 6: Comparison of the Transmission Loss in this Study and the Bolton Theory in B-U Structure 
The negligible difference between two diagrams is due to the method of programming and the used software. In this paper, the MATLAB software has been used and solving the equation set is done by Gauss elimination method. The parameters are similar to the Bolton parameters, which is presented in Table 1. Aluminum panels are uses as an elastic layers.

Table 1: Used Parameters in the Bolton Research

\begin{tabular}{ll}
\hline Value & Parameter \\
\hline $7 \times 10^{10}$ & Aluminum Young modulus $(\mathrm{Pa})$ \\
0.33 & Aluminum Poisson ratio \\
2700 & Aluminum density $(\mathrm{kg} / \mathrm{m} 3)$ \\
$1.27 \times 10^{-3}$ & Aluminum thickness of first layer $(\mathrm{m})$ \\
$0.762 \times 10^{-3}$ & Aluminum thickness of second layer $(\mathrm{m})$ \\
30 & Bulk density of solid phase $(\mathrm{kg} / \mathrm{m} 3)$ \\
7.8 & The geometrical structure factor \\
0.9 & Porosity \\
$8 \times 10^{5}$ & Static Young modulus $(\mathrm{Pa})$ \\
0.265 & Loss coefficient \\
0.4 & Poisson ratio \\
$25 \times 10^{3}$ & Flow resistance $(\mathrm{MKS} \mathrm{Rayls} / \mathrm{m})$ \\
$27 \times 10^{-3}$ & Thickness of foam layer $(\mathrm{m})$ \\
$14 \times 10^{-3}$ & Thickness of air gap $(\mathrm{m})$ \\
\hline
\end{tabular}

The air gap plays a determining role in the transmission loss values of B-U structure. The model is investigated for different fluids, whose characteristics are given in Table 2 (see Fig. 7)

Table 2: Fluids Filling the Air Gap

\begin{tabular}{llll}
\hline$v\left(\mathrm{~m}^{2} / s\right)$ & $c(\mathrm{~m} / \mathrm{s})$ & $\rho\left(\mathrm{kg} / \mathrm{m}^{3}\right)$ & Fluid \\
\hline $1.51 \times 10^{-5}$ & 344 & 1.2 & Air \\
$2.942 \times 10^{-5}$ & $1.23 \times 10^{3}$ & $1.2 \times 10^{3}$ & NMF-128DV \\
$4.2 \times 10^{-4}$ & $1.7 \times 10^{3}$ & $8.8 \times 10^{2}$ & Oil-SAE 30 \\
\hline
\end{tabular}

As shown in Fig. 7, using a Nano-fluid or oil may increase the sound transmission loss values within the low frequency about an average of $15 \mathrm{~dB}$ and at the high frequencies about an average of $30 \mathrm{~dB}$.

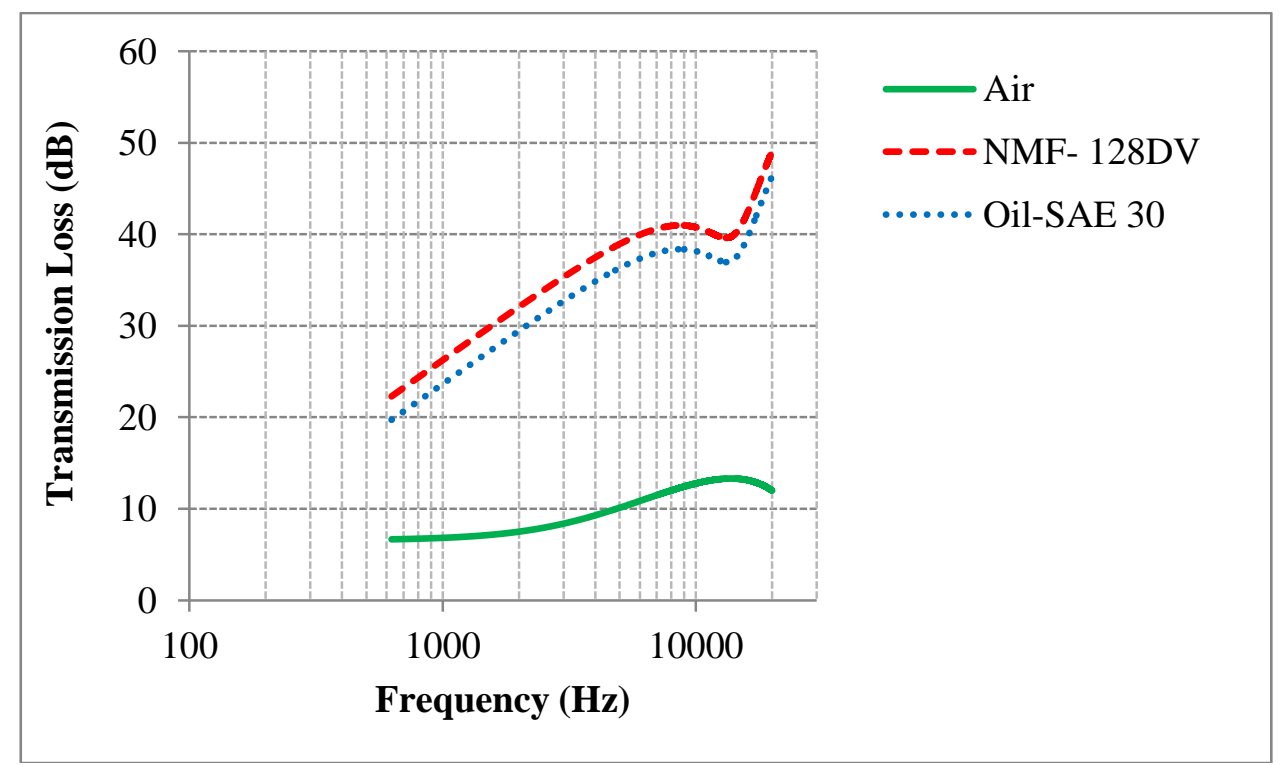

Fig. 7: The Effect of the Fluid Filling the Gap on the Values of the Transmission Loss in the B-U Structure

Fig. 8 shows the transmission loss values for different gap lengths. In a wide range of frequencies between the first and second resonant frequency, by increasing air gap, transmission loss values increases up to $7 \mathrm{~dB}$. Also, the resonant frequency decreased from $19.9 \mathrm{kHz}$ to $12 \mathrm{kHz}$. 


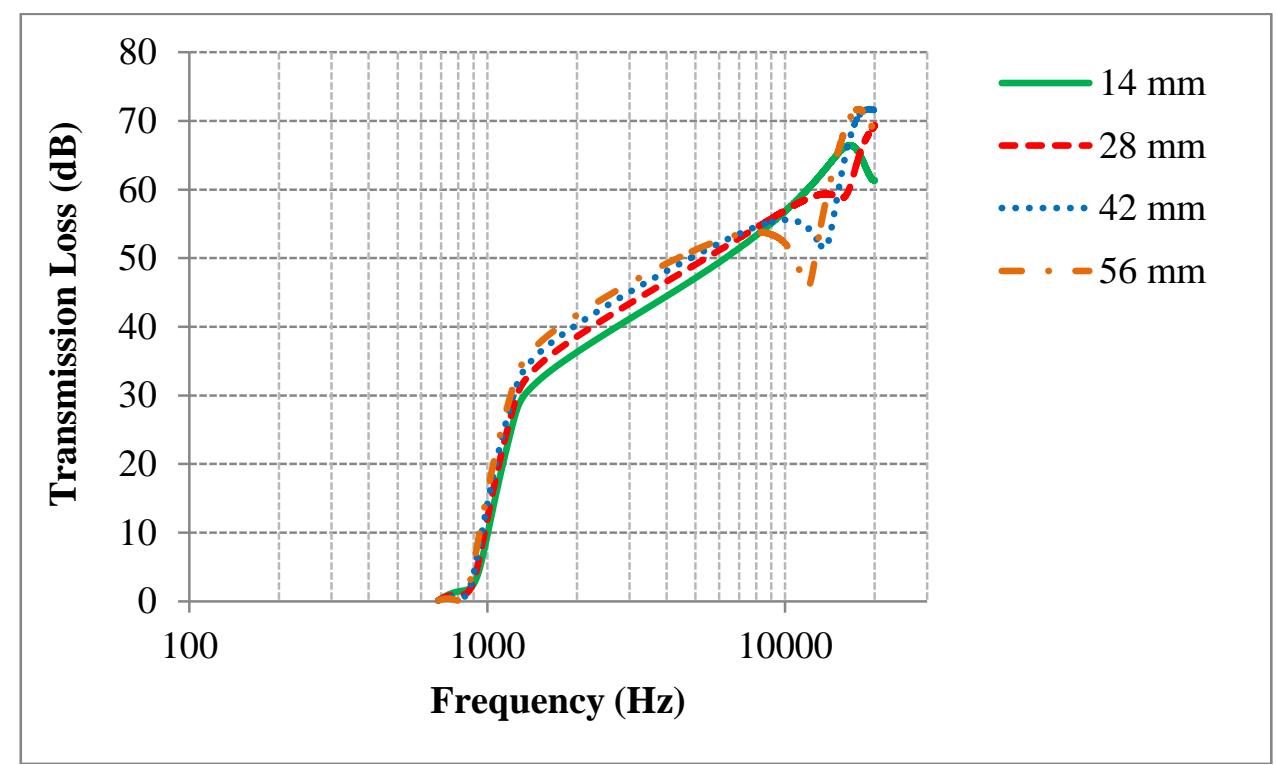

Fig. 8: The Effect of the Length of the Air Gap on the Values of Transmission Loss in the B-U Structure

As it can be observed from Fig. 9, by increasing the density of elastic layer from 2,700 kg/m3 to 5,940 kg/m3, values of transmission loss increases up to $10 \mathrm{~dB}$ (according to the mass law). Also, increasing the density of the layers decreases the resonance frequencies slightly (up to $20 \mathrm{~Hz}$ ). For each material, the mass law is valid only within a specified range of frequencies and there exists other factors that could affect the ability to absorb sound.

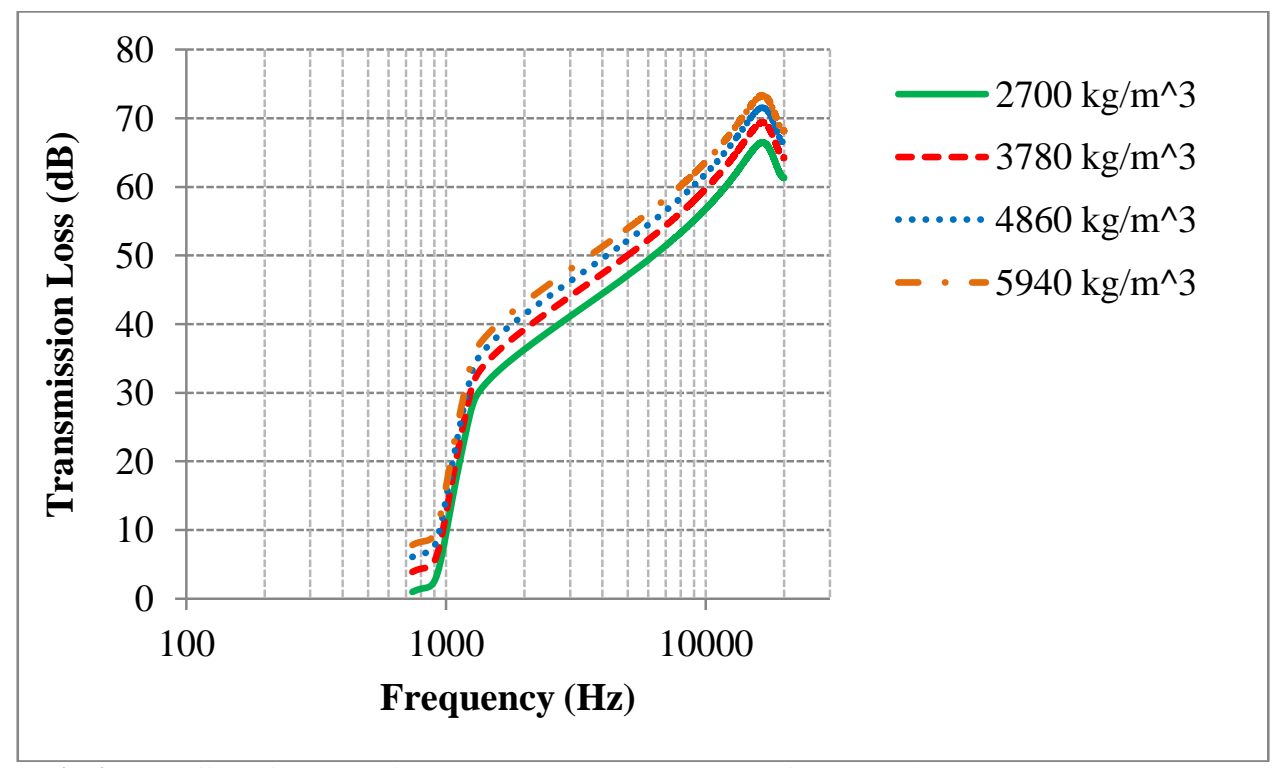

Fig. 9: The Effect of Density of the Elastic Layers on the Values of Transmission Loss in the B-U Structure

It is clear that the by increasing the thickness of the elastic planes, acoustic insulation properties are also improved. But thickening the walls is limited due to the increase in cost and also occupying the interior. In some cases, instead of using middle layer, the mechanical spring is used between the rigid planes and there exists only an air gap between the panels. The advantage of this method is reducing the required thickness to achieve the desired values of transmission loss. Furthermore, the material of the elastic layer and its effect on the values of the transmission loss is investigated. Material and properties of elastic layer is provided Table 3.

In Fig. 10, the transmission loss values of the different elastic layers are shown. In a wide range of frequencies, the steel has the highest transmission loss and resin has the lowest transmission loss. This is due to the fact that between the selected materials, steel has the highest density and resin has the lowest density. 


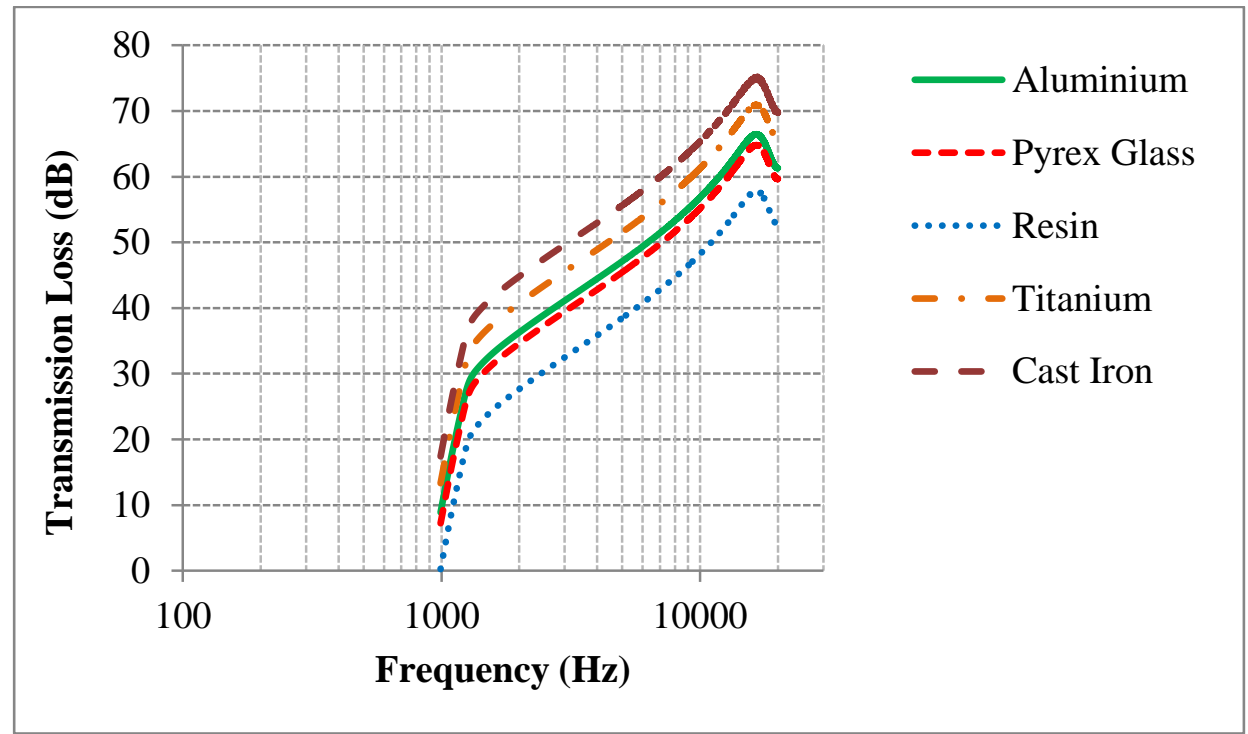

Fig. 10: The Material Effect of the Elastic Layer on the Transmission Loss in the B-U Structure

Table 3: List of Selected Materials for the Elastic Layer

\begin{tabular}{llll}
\hline Density $(\mathrm{kg} / \mathrm{m} 3)$ & Elasticity $(\mathrm{Pa})$ & Poisson ratio & Material \\
\hline 2700 & $70 \times 10^{9}$ & 0.33 & Aluminium \\
2230 & $67 \times 10^{9}$ & 0.2 & Pyrex glass \\
1000 & $1 \times 10^{8}$ & 0.45 & Resin \\
7800 & $2.1 \times 10^{11}$ & 0.31 & Steel \\
4500 & $1.1 \times 10^{11}$ & 0.34 & Titanium \\
\hline
\end{tabular}

In Fig. 11, the effect of the thickness of the middle porous layer on the transmission loss is shown. By increasing the thickness of the middle layer of porous material from 27 to $43.2 \mathrm{~mm}$, In the lower frequencies, (1 kHz to $5 \mathrm{kHz})$, we can see a reduction in the values of transmission loss about $7 \mathrm{~dB}$ and in the upper frequencies (between $5 \mathrm{ko} 10 \mathrm{kHz}$ ), a 10 $\mathrm{dB}$ increase can be seen. Therefore, depending on the used frequency range, the desired values can be obtained by changing the thickness of the porous layer.

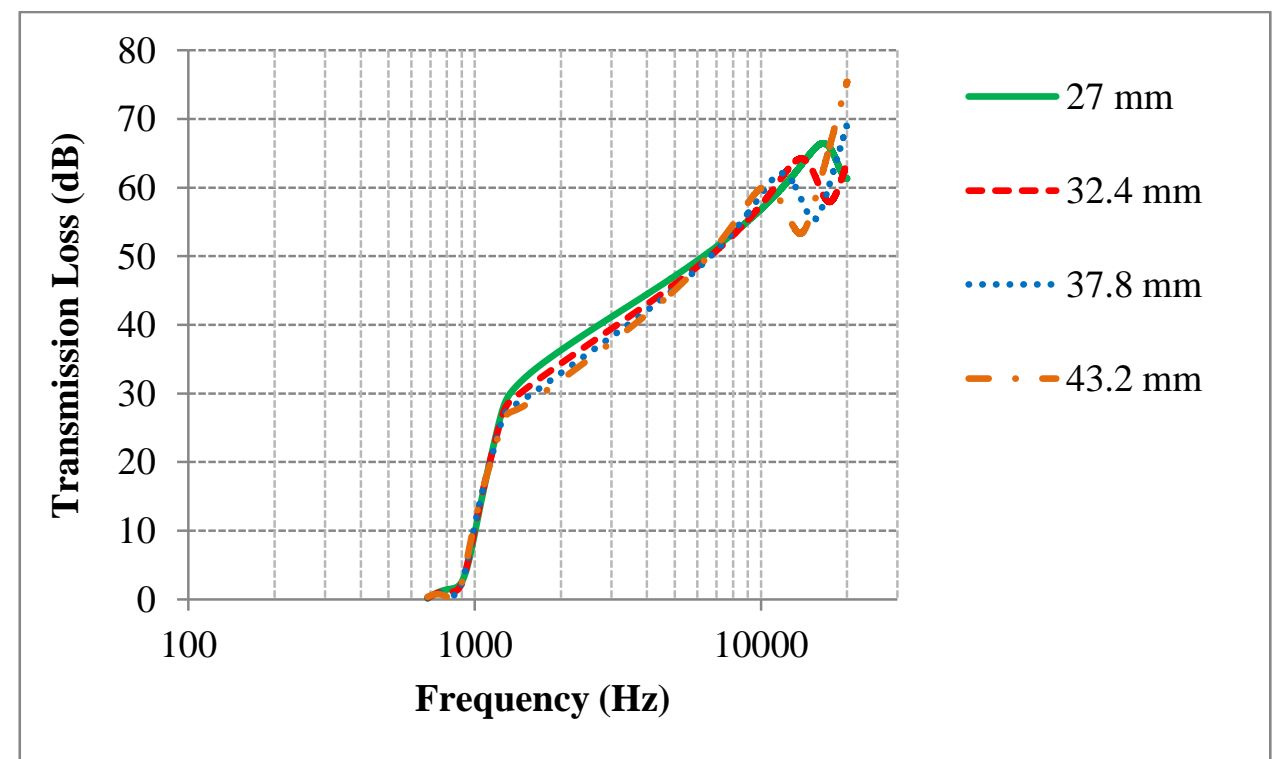

Fig. 11: The Effect of Porous Material Middle Layer Thickness on the Transmission Loss in the B-U Structure

In Fig. 12, the effect of different environmental conditions (different heights are provided in the Table 4), on the transmission loss values is shown. Higher heights influence on the density and sound velocity of the fluid. By increasing height, the acoustic resistance of the external fluid is reduced, so, the difference between the resistance of the 
acoustic wave and the passing wave, results in heterogeneity of acoustic impedance. In a wide range of frequencies, increasing the heterogeneity of acoustic impedance increases the transmission loss up to $7 \mathrm{~dB}$.

Table 4: The Different Environmental Conditions

\begin{tabular}{lllll}
\hline 4 & 3 & 2 & 1 & Environmental conditions \\
\hline 10650 & 7600 & 3050 & 0 & Height $(\mathrm{m})$ \\
0.379 & 0.5489 & 0.9041 & 1.2 & Density $(\mathrm{kg} / \mathrm{m} 3)$ \\
296.5 & 309.96 & 328.55 & 344 & Sound velocity $(\mathrm{m} / \mathrm{s})$ \\
\hline
\end{tabular}

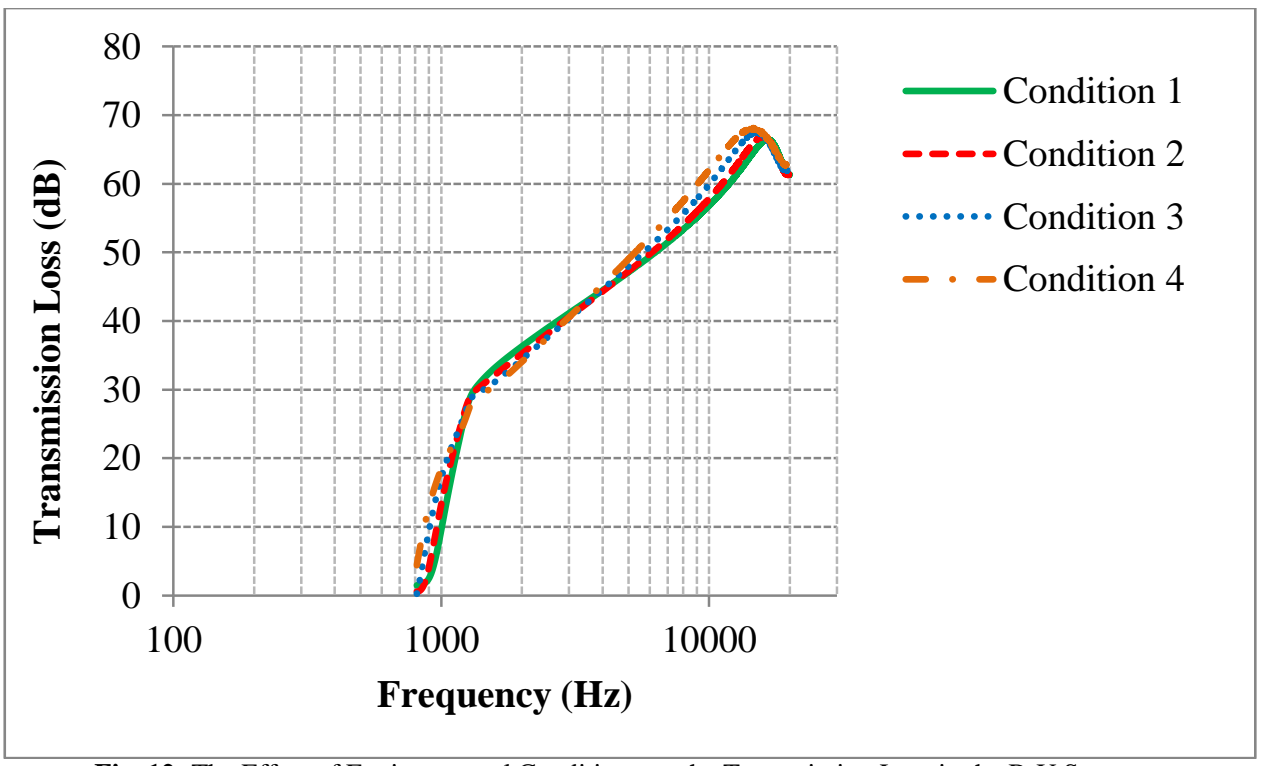

Fig. 12: The Effect of Environmental Conditions on the Transmission Loss in the B-U Structure

Next, the effect of macroscopic parameters of the porous material on the sound transmission loss is investigated. In Fig. 13, the effect of porosity, one of the important macroscopic parameters of porous materials, have been investigated. By changing this ratio from 0.3 to one (to reach the fluid phase), in a wide range of frequencies, the transmission loss reduced by the rate of $15 \mathrm{~dB}$. Form the Fig. 13, it can be concluded that the use of porous materials in the middle layer, in comparison with the fluid, increases the transmission loss.

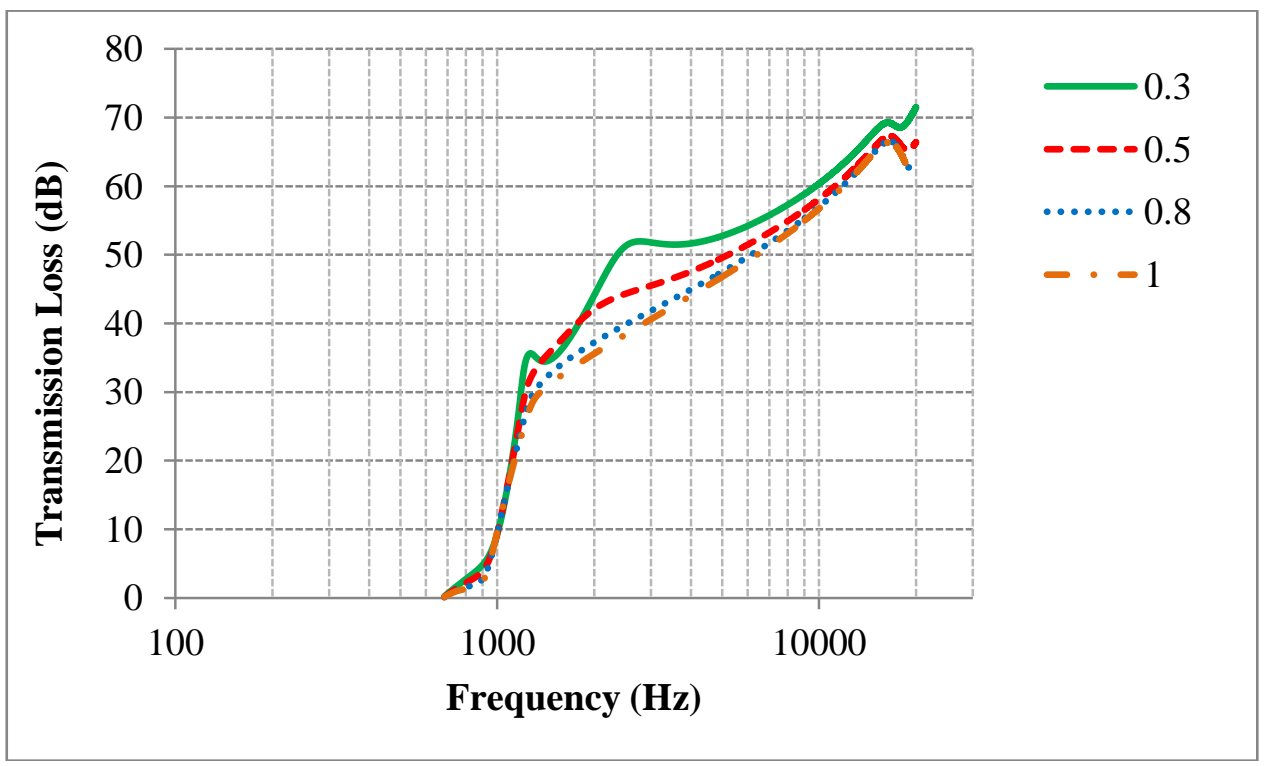

Fig. 13: The Effect of Absorbent Material Porosity on Transmission Loss in the B-U Structure

In Fig. 14, the effect of the solid phase bulk density of porous material on the transmission loss has been shown. In a wide range of frequencies, increasing the bulk density, the transmission loss increases up to $7 \mathrm{~dB}$. 


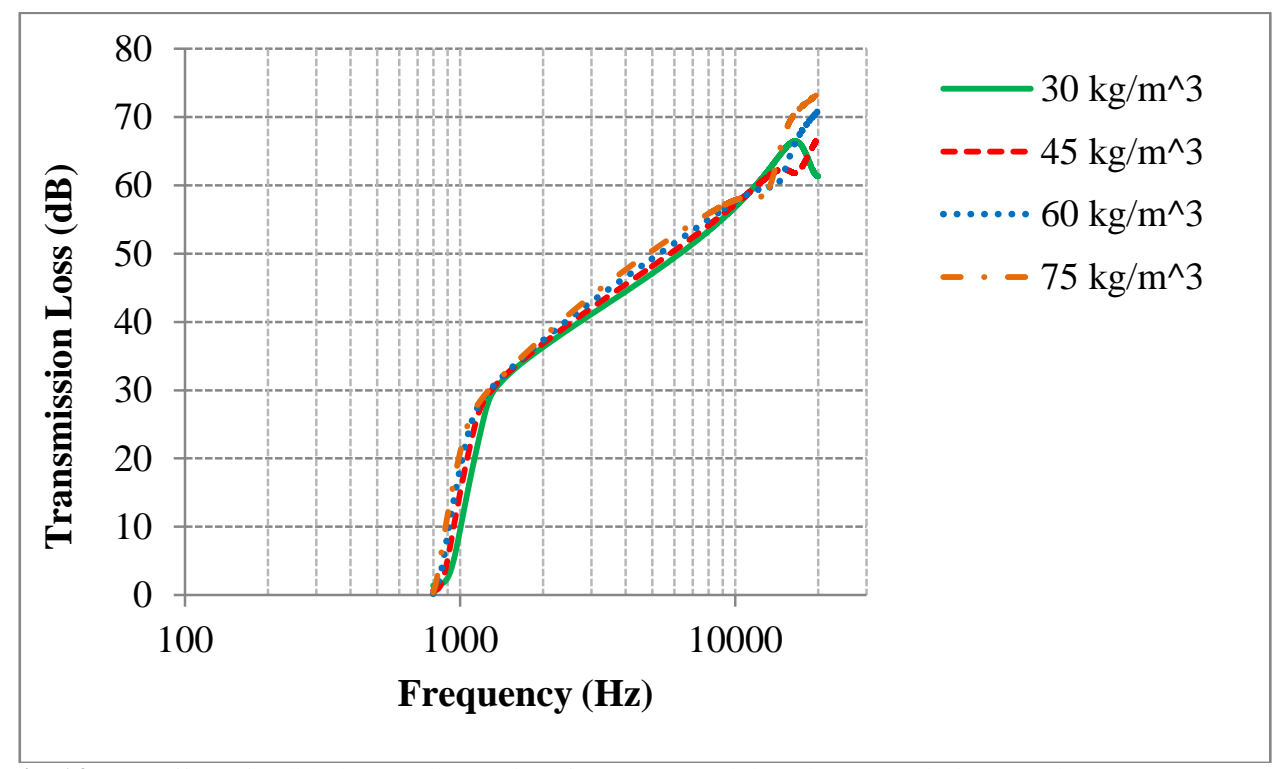

Fig. 14: The Effect of Solid Phase Bulk Density of Porous Material on the Transmission Loss in the B-U Structure

In the Fig. 15, the effect of viscosity of the middle layer of porous material on transmission loss has been shown. By increasing the viscosity from $25 \times 10^{3}$ to $10^{5}$, up to the frequencies of $15 \mathrm{kHz}$, the transmission loss reduced $5 \mathrm{~dB}$ and in the range of above $15 \mathrm{kHz}$, increases $7 \mathrm{~dB}$. Therefore, depending on the desired frequency range, you can use the porous layer with suitable viscosity to achieve desired transmission loss. Also, by changing the viscosity, the resonant frequencies are not moved.

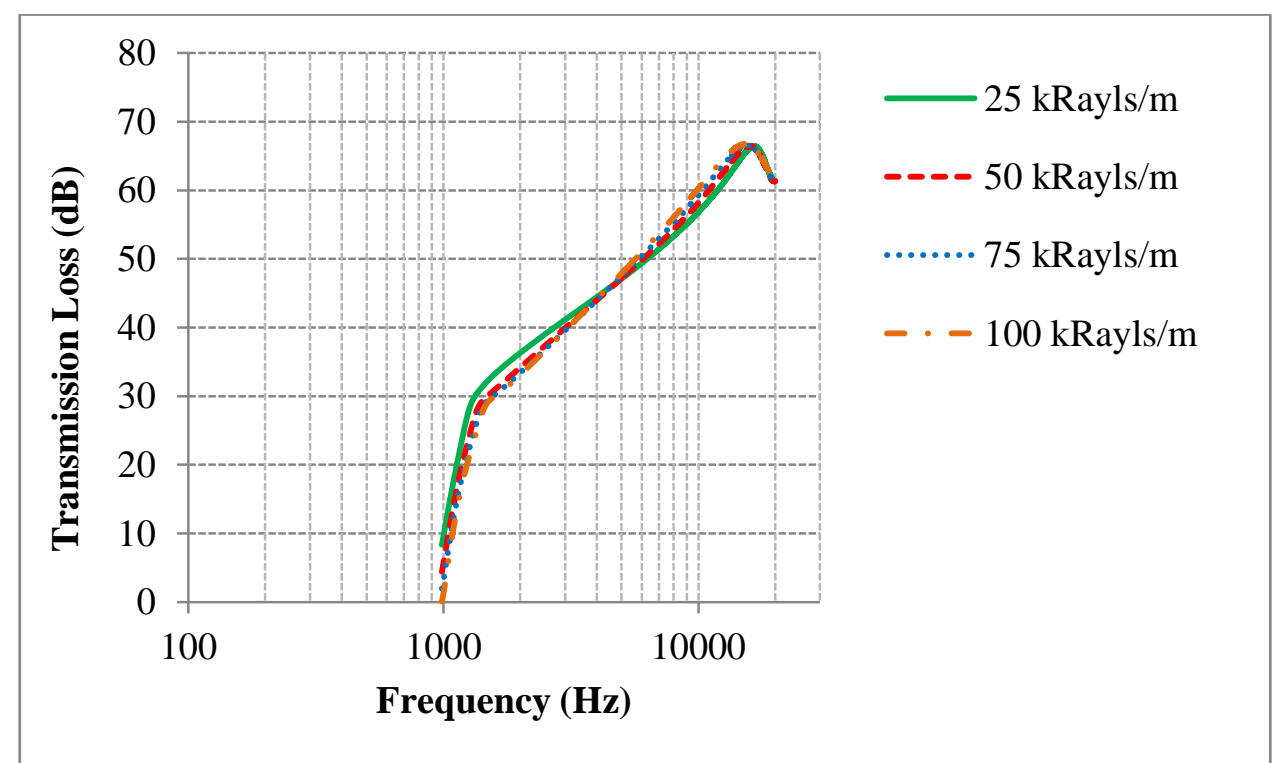

Fig. 15: The Effect of Viscosity of the Middle Layer of Porous Material on Transmission Loss in the B-U Structure

In Fig. 16, the geometrical structure factor of porous materials is studied. As we can observed an increase in the frequencies below $17 \mathrm{kHz}$, results in reduction in transmission loss about $7 \mathrm{~dB}$, at frequencies above $17 \mathrm{kHz}$, results in increase in the transmission loss about $20 \mathrm{~dB}$. As it can be observed at frequencies above the resonance frequency, analyzing and predicting the amount of increase or decrease of transmission loss is very complicated due to the complexity of the geometrical structure factor and simplification in its relationship. 


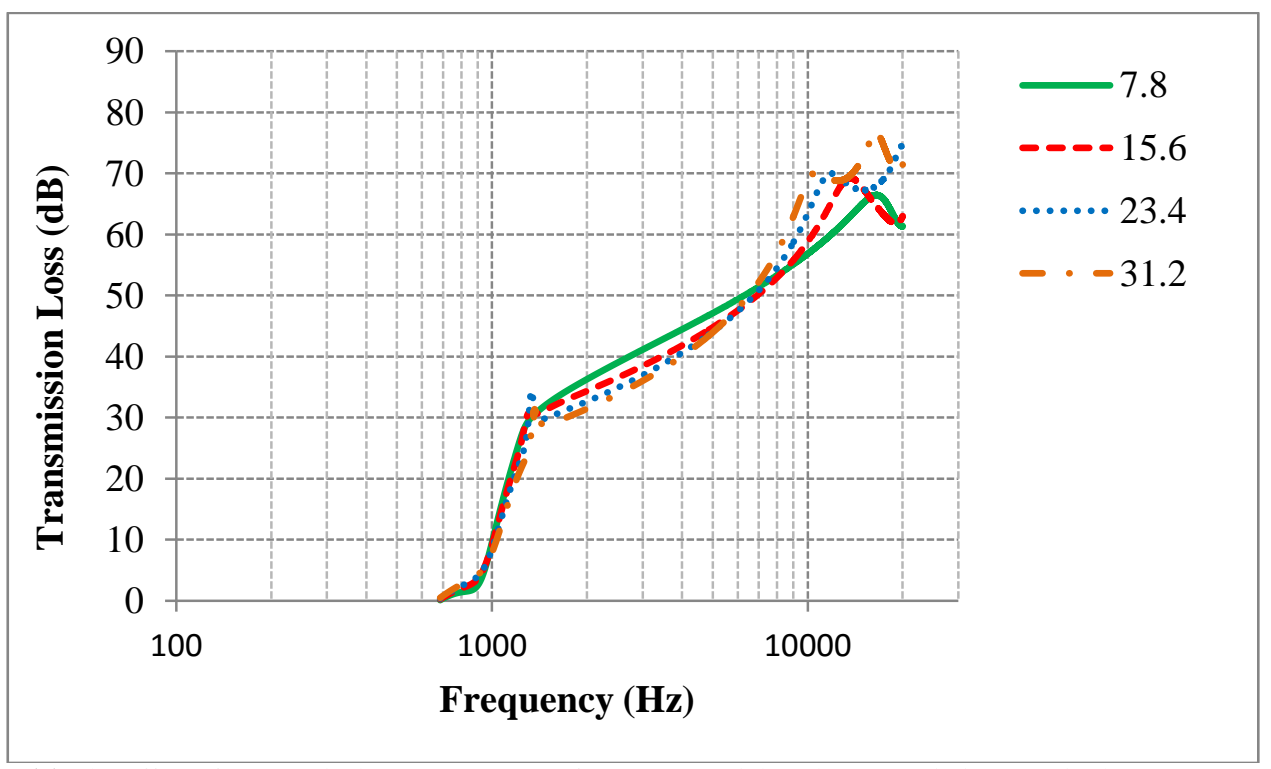

Fig. 16: The Effect of Geometrical Structure Factor of Porous Material on the Transmission Loss in the B-U Structure

In Fig. 17, the effect of static Young's modulus of porous material on transmission loss has been shown. In a wide range of frequencies, by increasing Young's modulus, transmission loss has decreased up to $12 \mathrm{~dB}$. Also, increasing this parameter has no effect on the resonance frequency.

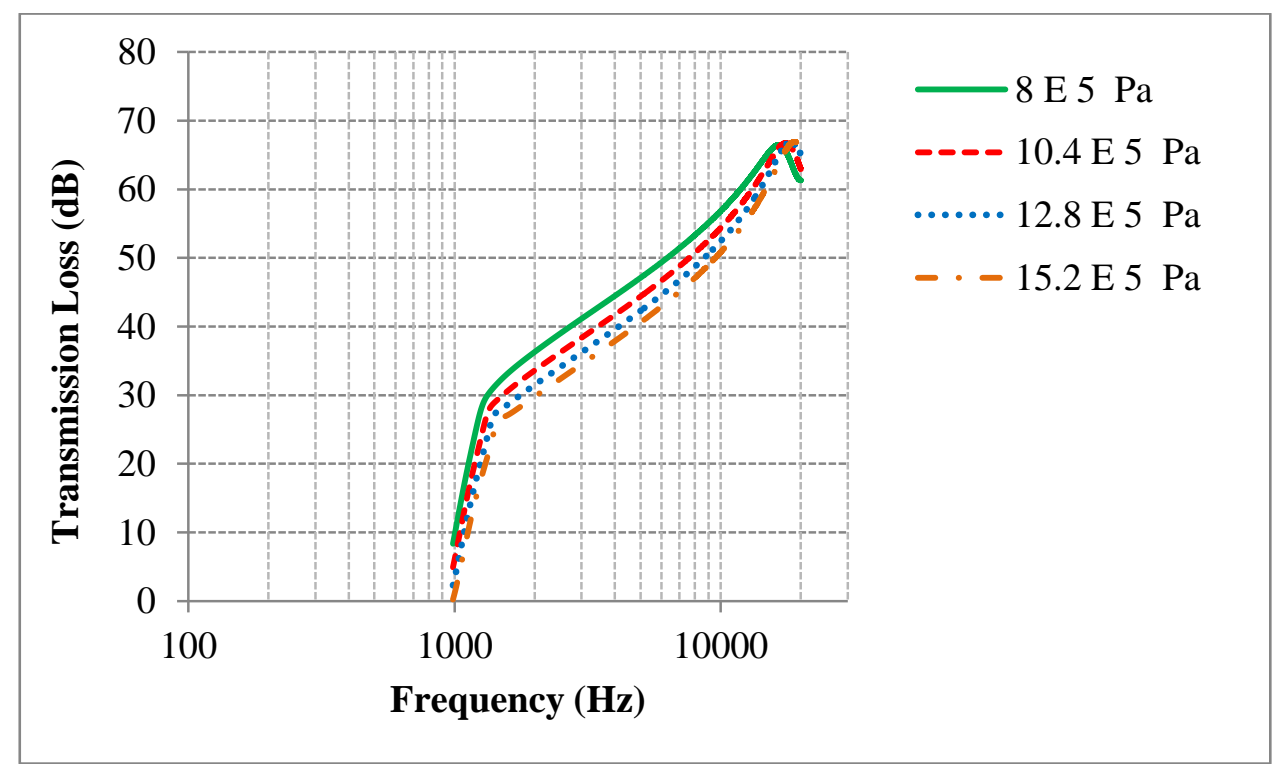

Fig. 17: The Effect of Static Young's Modulus of Porous Material on Transmission Loss in the B-U Structure

In Fig. 18, the loss coefficient of porous material is investigated. By increasing this parameter in a wide range of frequency, transmission loss decreases up to the $5 \mathrm{~dB}$. Due to the complexity of this parameter, as well as the geometrical structure factor, after passing the resonant frequencies, some deviation can be observed in the diagrams. 


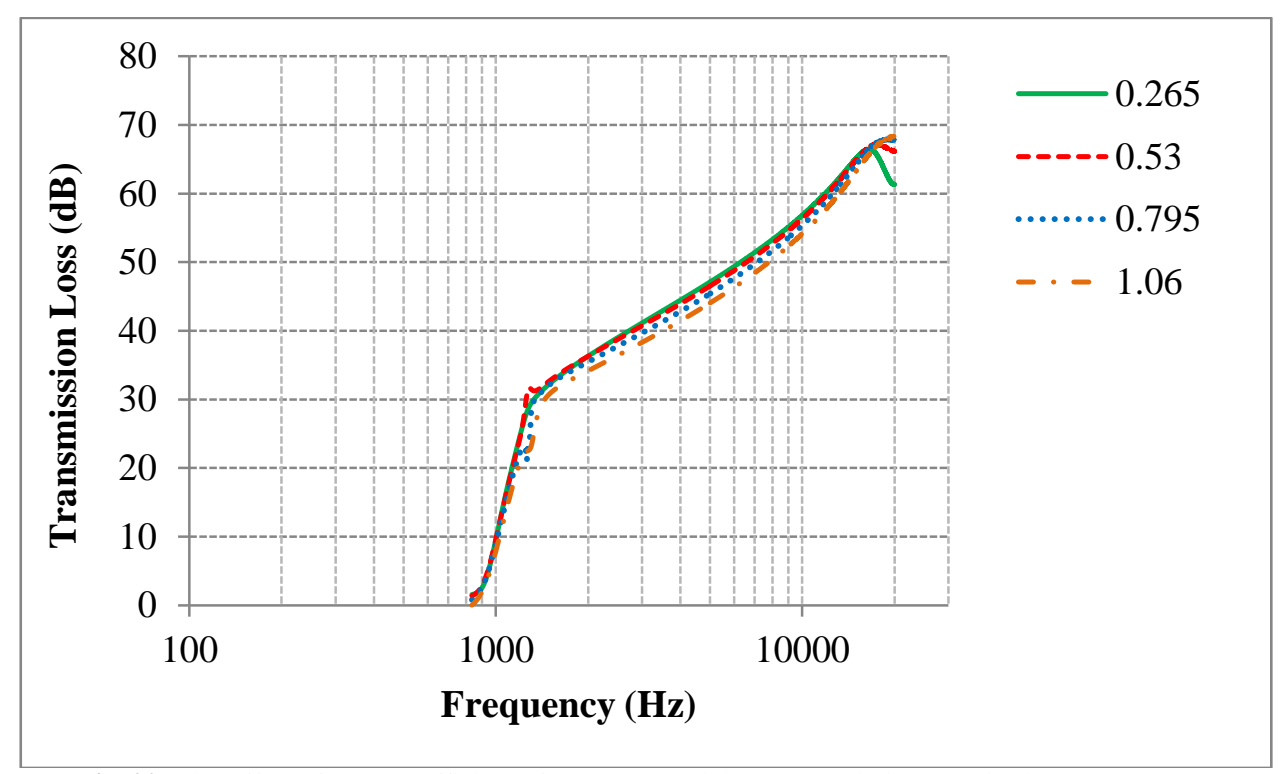

Fig. 20: The Effect of Loss Coefficient of Porous Material on Transmission Loss in the B-U Structure

\section{Conclusion}

In this Research, the sound transmission loss of a triple-layered panel with sound-absorbing intermediate layer materials in the normal incidence field has been calculated. The porous material is used as an absorbent layer between two elastic panels. In modeling these triple-layered panels, theory of wave propagation in porous materials is used and bounded boundary condition of the first elastic layer and unbounded boundary condition of the second elastic layer (B-U structure) is applied. To validate the model, the results of this model are compared with the results of the Bolton. Comparison of results revealed very good compatibility.

Here, the effect of the length of the air gap between the elastic layers, density and the material of the elastic plate, the thickness of the intermediate porous material and vibro-acoustic properties of porous material, on the values of transmission loss is investigated. In B-U structure the air gap has an important role in the transmission loss values. Using fluid in the air gap can be increase the sound transmission loss in the range of low frequencies, about of $15 \mathrm{~dB}$ and at the upper frequencies about of $30 \mathrm{~dB}$. In a wide range of frequencies between the first and second resonant frequency, by increasing air gap, transmission loss increases up to $7 \mathrm{~dB}$. In the frequency range of $600 \mathrm{~Hz}$ to $20 \mathrm{kHz}$, by increasing the density of elastic layers from 2700 to $5940 \mathrm{~kg} / \mathrm{m} 3$, transmission loss increases about $10 \mathrm{~dB}$. Increasing the density of elastic layers reduces the resonance frequencies of a small amount (up to $20 \mathrm{~Hz}$ ).in a wide range of frequencies, using the elastic layers of steel, results in maximum amount of transmission loss and resin elastic layers results in lowest transmission loss. Thus, by increasing the density of the elastic layer, transmission loss values can be increased by $20 \mathrm{~dB}$.

By increasing the thickness of the porous layer from $27 \mathrm{~mm}$ to $43.2 \mathrm{~mm}$, at frequencies range of $1 \mathrm{kHz}$ to $5 \mathrm{kHz}$, the values of the transmission loss decreases about $7 \mathrm{~dB}$ and in frequencies range from 5 to $10 \mathrm{kHz}, 10 \mathrm{~dB}$ increase can be seen. By increasing the porous material porosity from 0.3 to 1 (to reach the fluid phase) the values of the transmission loss show $5 \mathrm{~dB}$ reductions. In a wide range of frequencies, increasing the bulk density, the transmission loss increases up to $7 \mathrm{~dB}$. By increasing the viscosity up to the frequencies of $15 \mathrm{kHz}$, the transmission loss reduces $5 \mathrm{~dB}$ and in the range of above $15 \mathrm{kHz}$, increases $7 \mathrm{~dB}$. An increase in the factor of geometrical structure, in the frequencies below 17 $\mathrm{kHz}$, results in reduction in transmission loss about $7 \mathrm{~dB}$ and at frequencies above $17 \mathrm{kHz}$, results in increase in the transmission loss about $20 \mathrm{~dB}$. In a wide range of frequencies, by increasing Young's modulus, transmission loss has decreased up to $12 \mathrm{~dB}$. By increasing the loss coefficient of the porous material parameter in a wide range of frequency, transmission loss decreases up to the $5 \mathrm{~dB}$. Increasing the height, increase the heterogeneity of impedance in the frequency range of $1.3 \mathrm{kHz}$ to $20 \mathrm{kHz}$, increases the transmission loss up to $7 \mathrm{~dB}$.

\section{References}

[1] M. A. Biot, "Theory of propagation of elastic waves in a fluid-saturated porous solid. I. low frequency range", Journal of the Acoustical Society of America, 28, 2, (1956), 168-191.

[2] M. A. Biot, "Theory of propagation of elastic waves in a fluid-saturated porous solid. II. Higher frequency range", Journal of the Acoustical Society of America, 28, (1956) 179-191. http://dx.doi.org/10.1121/1.1908241.

[3] J. S. Bolton, E. R. Green, "Normal incidence sound transmission through double-panel systems lined with relatively stiff, reticulated polyurethane foam", Applied Acoustics, 39, (1993), 23-51. http://dx.doi.org/10.1016/0003-682X(93)90028-5.

[4] R. Panneton, N. Atalla, J. F. Allard, "A 3-D finite element model for sound transmission through a double-plate system with isotropic elastic porous materials", Journal of the Acoustical Society of America, 96, (1994), 33-39. http://dx.doi.org/10.1121/1.410669. 
[5] J. S. Bolton, N. M. Shiau, Y. J. Kang, "Sound transmission through Multi-Panel Structures Lined with Elastic porous Materials", Journal of Sound and Vibration, (1996), 317-347. http://dx.doi.org/10.1006/jsvi.1996.0125.

[6] Y. Y. Tang, J. H. Robinson, R.J. Silcox, "Sound transmission through a cylindrical sandwich shell with honeycomb core", 34th AIAA Aerospace Science Meeting and Exhibit, AIAA-96-0877, (1996), 1-10.

[7] N. Atalla, R. Panneton, M. Tournour, C. K. Amedin, 1998, "Sound transmission through multilayer structures with isotropic elastic porous materials", Journal of the Acoustical Society of America, 103, (1998), 29-40. http://dx.doi.org/10.1121/1.422157.

[8] J. H. Lee, J. Kim, "Simplified method to solve sound transmission through structures lined with elastic porous material", Journal of the Acoustical Society of America, 110, 5, (2001), 2282-2294.

[9] M. J. Mahjoob, N. Mohammadi, S. Malakooti, "An investigation into the acoustic insulation of triple-layered panels containing Newtonian fluids: theory and experiment", Applied Acoustics, 70, (2009), 165-171. http://dx.doi.org/10.1016/j.apacoust.2007.12.002.

[10] N. Mohammadi, M. J. Mahjoob, "Transmission loss of multilayer panels containing a fluid using progressive wave model: comparison with impedance progressive model and experiments", Comptes Rendus Mécanique, 337, (2009), 198-207. http://dx.doi.org/10.1016/j.crme.2009.05.001.

[11] S. Malakooti, N. Mohammadi, M. J. Mahjoob, K. Mohammadi, "Identification of adhesive bond in a multi-layered structure via sound insulation characterestics", Journal of Mechanics, 26, (2010), 113-122.

[12] M. J. Mahjoob, N. Mohammadi, S. Malakooti, "Analytical and experimental evaluation of magnetic field effect on sound transmission loss of MR-based smart multi-layered panels", Applied Acoustics, 73, (2012), 614-623. http://dx.doi.org/10.1016/j.apacoust.2011.12.015.

[13] K. Daneshjou, H. Ramezani, R. Talebitooti, "Wave transmission through laminated composite double-walled cylindrical shell lined with porous materials", Applied Mathematics and Mechanics, 32, 6, (2011), 1-16.

[14] M. H. Shojaeifard, R. Talebitooti, M. A. Molla, "A Study of Intake System Noise Transmission with Porous Insulator Using statistical Energy Analysis", International Journal of Automotive engineering, 2, 1, (2012), 8-20.

[15] J. F. Allard, A. Aknine, C. Depollier, "Acoustical properties of partially reticulated foams with high and medium flow resistance", Journal of the Acoustical Society of America, 79, (1986), 1734-1740. http://dx.doi.org/10.1121/1.393234.

[16] J. F. Allard, C. Depollier, W. Lauriks, "Measurement and prediction of surface impedance at oblique incidence of a plastic foam of high flow resistivity", Journal of Sound and Vibration, 132, (1989), 51-60. http://dx.doi.org/10.1016/0022-460X(89)90870-5.

[17] M. A. Biot, D. G. Willis, "The elastic coefficients of the theory of consolidation", Journal of Applied Mechanics, 24, (1957), 594-601.

[18] N. M. Shiau, "Multi-dimensional wave propagation in elastic porous materials with applications to sound absorption, transmission and impedance measurement", Ph.D. Thesis, School of Mechanical Engineering, Purdue University, (1991). 